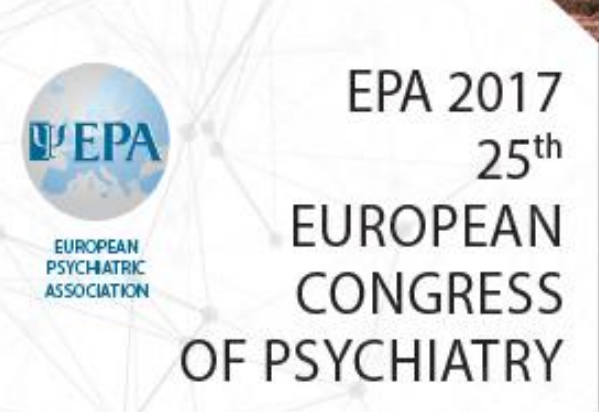

\title{
TIME SPENT IN RETIREMENT, HEALTH AND WELL-BEING
}

Ana Rita Lucas ${ }^{(1)}$, Fernanda Daniel(2,3), Sónia Guadalupe ${ }^{(2,4)}$, Ilda Massano(2) Henrique Testa Vicente ${ }^{(2,4)}$

(1) MA in Clinical Psychology - Miguel Torga Institute of Higher Education (ISMT), (2) Assistant Professor - ISMT, (3) Center of Study and Research in Health (CEISUC), (4) Research Centre for the Study of Population, Economics and Society (CEPESE)

Introduction: From a life-span developmental perspective, retirement can be considered a life event that entails a complex psychological challenge, including leaving one's professional life and organizing/enjoying the newly available free time. The literature about retirement identifies different stages (Atchley, 1976) and patterns of transition/adaption (Fonseca, 2004) associated with time spent in retirement.

Objectives: To analyze the association between time spent in retirement and subjective measures of mental health, depressive symptomatology, loneliness and satisfaction with life.

\section{Method:}

Measures: MHI-5 - Mental Health Inventory (Ribeiro, 2001); Geriatric Depression Scale (Short Form) (Yesavage et al., 1983; Almeida \& Almeida, 1999); UCLA Loneliness Scale (Neto, 1989) ; SWLS - Satisfaction With Life Scale (Diener et al., 1985). All the instruments demonstrated good internal consistency (Cronbach's alpha scores between 0,70 and 0,90 ). Sample: The sample was comprised of 641 participants, with a mean age of 74,86 years (ranging from 55 to 98 years); $63,5 \%(n=407)$ were women. Regarding marital status, $343(53,5 \%)$ participants were married or cohabiting, 224 $(34,9 \%)$ were widowed, $45(7,0 \%)$ never married, and $29(4,5 \%)$ were divorced or separated.

Results: Statistically significant differences in all the health and well-being variables addressed were found between subgroups of time spent in retirement (MHI-5: $p=0.001$; GDS: $p<0.001$; UCLA: $p=0.038$; SWLS: $p=0.022$ ). Mental health and satisfaction with life increases in the first year after retirement, but during the second year they decrease to the levels found in pre-retirement. Loneliness and depressive symptomatology follow an inverted pattern. With the passing of years, loneliness and depression tend to increase; mental health and satisfaction with life tend to decrease.

Table 1. Subjective measures of health and well-being according to time spent in retirement

\begin{tabular}{|c|c|c|c|c|c|c|c|c|c|c|c|c|c|c|c|c|}
\hline & \multicolumn{14}{|c|}{ Time spent in retirement (in months) } & \multirow[b]{3}{*}{$x^{2}$} & \multirow[b]{3}{*}{$p$} \\
\hline & \multicolumn{2}{|c|}{ Still working } & \multicolumn{2}{|c|}{$1-12$} & \multicolumn{2}{|c|}{$13-24$} & \multicolumn{2}{|c|}{$25-60$} & \multicolumn{2}{|c|}{$61-120$} & \multicolumn{2}{|c|}{$121-240$} & \multicolumn{2}{|c|}{+240} & & \\
\hline & M & $S D$ & M & $S D$ & M & $S D$ & M & $S D$ & M & $S D$ & $M$ & $S D$ & M & $S D$ & & \\
\hline MHI-5 & \multicolumn{2}{|c|}{$n=53$} & \multicolumn{2}{|c|}{$n=25$} & \multicolumn{2}{|c|}{$n=27$} & \multicolumn{2}{|c|}{$n=55$} & \multicolumn{2}{|c|}{$n=117$} & \multicolumn{2}{|c|}{$n=207$} & \multicolumn{2}{|c|}{$n=155$} & & \\
\hline GDS & 3,96 & 2,69 & 2,12 & 2,67 & 3,31 & 3,16 & 3,73 & 3,69 & 4,25 & 3,36 & 5,23 & 3,74 & 6,33 & 3,83 & 58,7 & $<0,001^{* *}$ \\
\hline \multirow[t]{2}{*}{ UCLA } & 30,85 & 6,81 & 29 & 7,55 & 31,3 & 6,45 & 30,89 & 7,2 & 31,69 & 7,88 & 32,85 & 8,53 & 33,97 & 8,55 & 13,36 & $0,038^{\star *}$ \\
\hline & \multicolumn{2}{|c|}{$n=53$} & \multicolumn{2}{|c|}{$n=25$} & \multicolumn{2}{|c|}{$n=27$} & \multicolumn{2}{|c|}{$n=55$} & \multicolumn{2}{|c|}{$n=117$} & \multicolumn{2}{|c|}{$n=208$} & \multicolumn{2}{|c|}{$n=155$} & & \\
\hline \multirow[t]{2}{*}{ SWLS } & 17,81 & 4,58 & 18,76 & 3,63 & 17,44 & 3,86 & 17,51 & 4,29 & 16,89 & 4,55 & 16,55 & 4,93 & 15,91 & 4,57 & 14,81 & $0,022^{* *}$ \\
\hline & & & & & & & & & & & & & & & & \\
\hline
\end{tabular}

Discussion/Conclusions: The results provide support to the hypotheses of "honeymoon" and "disenchantment" phases in the recently retired (Atchley, 1976) and to the existence of different patterns of transition/adaptation associated with time spent in retirement. The results seem to fit the developmental scheme proposed by Fonseca (2004), in which a pattern of Openness-Gains characterizes early stages of retirement (positive attitude towards life and openness to the exterior) and a pattern of Losses-Disengagement characterizes those with more time spent in retirement (poor satisfaction and experience of loneliness). These results highlight the relevance of devising intervention strategies that enable individuals to maintain the levels of mental health and satisfaction achieved during the first phase of retirement.

Almeida, O. P., \& Almeida, S. A. (1999). Confiabilidade da Versão Brasileira da Escala de Depressão em Geriatria (GDS) versão reduzida. Arquivos de Neuro-Psiquiatria, 57(2 B), 421-426. https://doi.org/10.1590/S0004-282X1999000300013

Atchley, R. (1976). The sociology of retirement. Cambridge: Schenkman.

Fonseca, A. M. (2004). Uma abordagem psicológica da passagem à reforma desenvolvimento, envelhecimento, transição e adaptação. Dissertaçaa de dritoramento nao publicada. Instutode Ciências Biomédicas Abel Salazar, Porto.

Adey, M., \& Leirer, V. O. (1983). Development and validation of a geriatric depression screening scale: a preliminary report. Journal of Psychiatric Research, 17(1),37-49.

Ribeiro, J. (2001). Mental Health Inventory: um estudo de adaptação à população portuguesa. Psicologia, Saúde \& Doença, 2 (1), 77-99. Neto, F. (1989). Avaliação da solidăo. Psicologia Clínica, 2, 65-79.
Diener, E., Em
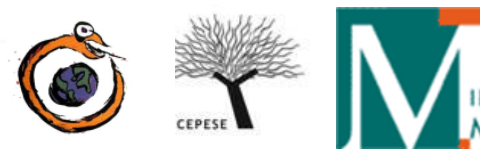